\title{
Papillomavirus (PV) - Associated Skin Diseases in Domestic and Wild Animals: Animal Nucleotide Sequence Identity of PV Types to their Closest Related PV and HPV Sequences Deposited in the Gen Bank
}

\author{
Rachel Siqueira de Queiroz Simões* and Ortrud Monika Barth
}

\author{
Laboratory of Morphology and Viral Morphogenesis, Instituto Oswaldo Cruz, Fundação \\ Oswaldo Cruz, Avenida Brasil 4365, Manguinhos, 21040-900, Rio de Janeiro, RJ, Brazil \\ *Corresponding author
}

\section{A B S T R A C T}

\begin{abstract}
Keywords
Animal

papillomavirus,

Genetic diversity,

Nucleotide

sequence,

Papillomarividae,

Polymerase chain

reaction.

Article Info

Accepted:

14 June 2017

Available Online:

10 July 2017
\end{abstract}

The papilloma viruses belong to the Papilloma viridae family and new genera were described on the basis of the interspecies phylogenetic similarity. They are DNA viruses that induce the formation of benign and malignant tumors in a vast range of hosts. The main objective of the present study was to detect PV DNA and papilloma virus-associated skin diseases in domestic and wild animals. This paper analyzed nucleotide sequence similarity of animal papilloma virus types to their closest related PV types and HPV sequences deposited in the Gen Bank. Genomic DNA was extracted from 75 blood samples and 18 warts-like lesions from several wild and domestic animals of the 15 following species: Ara ararauna, Ara chloroptera, Ara macao, Bos taurus, Bubalus bubalis, Canis familiaris, Equus caballus, Felis concolor, Macaca fascicularis, Ovis aries, Panthera leo, Panthera onca, Sus scrofa, Sus domesticus and Struthio camelus. Papilloma virus-associated skin diseases as papillomatosis, adenocarcinomas, nodular formations, melanoma and fibrous epulic lesions were diagnosed by histopathology. PV DNA bands of skin biopsy and blood samples from the animals submitted to amplification of the L1 ORF were detected. About 31 biological samples of animals of the eight species Ara chloroptera, Ara macao, Bos taurus, Canis familiaris, Felis concolor, Ovis aries, Panthera onca, Struthio camelus generated viral DNA fragments PCR amplified using degenerated primer pairs FAP59/FAP64. Nucleotide sequence similarities of animal papilloma virus types to their closest related PV types and HPV sequences deposited in Gen Bank were described suggesting that the sequences share the same ancestry of the genetic evolutionary.

\section{Introduction}

Papilloma viruses (PV) are classified in the Papilloma viridae family presenting 26 genera, 62 species and 69 known animal papilloma viruses with high genetic variability. New genotypes have been sequenced and classified on the basis in the interspecies phylogenetic similarity. Papilloma viruses are constituted of a closed circular double-stranded DNA genome, are non-enveloped, non-segmented with approximately $8 \mathrm{~kb}$ (Huber et al., 2017).

More than 200 types of PV have been described in humans, while only 20 types have been confirmed in animals. In some host species, multiple types of PV have been 
found, and the available data suggest some correlation between each type of PV, pathology and target tissue (epithelial tissue, stratified mucosal epithelium and mesenchymal cells of the dermis) (Chan et al., 1997). Previous studies had described immunological aspects and morphological structures associated HPV-positive in $\mathrm{SiHa}$ (HPV-16) and HeLa (HPV-18) cervical carcinoma cell lines (Simões and Barth, 2017).

Human HPV vaccination is the best preventive strategy against cervical cancer, cervical intraepithelial neoplasia and genital warts. Licensed HPV vaccines, being bivalent (Cervarix®) against HPV16/18, quadrivalent (Gardasil@) target HPV16/18/6/11 or nonavalent (Gardasil-9®) target HPV16/18/31/33/45/52/58/6/11, have been applied in many countries (Huber et al., 2017). Several potential benefits of vaccination have been associated in HPV related diseases as anus-genital cancer, head and neck cancer, colorectal tumors, penile cancer and recurring respiratory papillomatosis. Currently, the papillomavirus can be used as viral vectors in the gene therapy and new therapeutic targets have been successfully applied by recombinant DNA methods (Simões and Barth, 2015).

More than 16 putative new types of bovine papillomavirus (BPV) have been isolated, and more of them are continuously being discovered by complete genomic phylogenetic analysis of DNA sequences (Tomita et al., 2006). Cytogenetic studies in bovines detected premature chromosome condensation (PCC) in peripheral blood lymphocytes cultures and skin lesions cultures induced by papillomavirus spontaneous infection (Marins et al., 2010). Chromosome aberrations have been detected in cell cultures from bovines, canines and equines infected with papillomavirus and have been applied as a biomarker for genomic instability (Simões and Barth, 2016). Furthermore, bovine papillomavirus (BPV) virus-like particles (VLP) inside the cell nucleus had been demonstrated from warts bovines by electron microscopy (Simões and Barth, 2017).

Canine oral papillomavirus (COPV) induces cauliflower-like warts in the oral mucosa of domestic dogs, as well as in wild canids (Nicholls et al., 1999). Experimental infection with COPV observed during the period of four to eight weeks after inoculation, the development of papillomas followed by immune-mediated spontaneous regression (Nicholls et al., 1999). More than 95\% of COPV lesions regress within two to four weeks and only a few papillomas progress to more severe lesions, including oral squamous cell carcinoma (Ghim et al., 2000). Degenerated primers FAP59/FAP64 have been used to detected DNA sequences in canines latent papillomavirus infection (Marins et al., 2012).

According Hanna and Dunn (2003), 1.400 biopsies were performed on felines and, after clinical and microscope analysis tumors were diagnosed as cutaneous fibropapillomas. Previous studies have found cutaneous papillomas in the domestic cat (Felis domesticus) and the snow leopard (Panthera uncia). Papillomavirus induced intermediate ultrastructural aberrations in the viral assembly were observed inside the intracytoplasmatic inclusions of both animals (Sundberg et al., 2000).

A new papillomavirus type of $8.000 \mathrm{bp}$ DNA fragment was detected using Bam HI restriction endonuclease, different from the cutaneous lesions of domestic felines. It was identified as an Asian lion Panthera leo persica papillomavirus (PIPV) from a biopsy of the ventral surface of the tongue of free living and captivity animals (Sundberg et al., 
1996). Studies involving wild animals are rare. Clinically, small papillomas were found on the foot of an impala (Aepyceros melampus) and on the head of a giraffe (Giraffaca melopardalis) in Kenya, Africa (Karstad and Kaminjolo, 1978).

In monkeys, clinical and pathological findings suggest a positive infection containing Rhesus papillomavirus type 1 (RhPV-1) DNA integrated into the tumor cell DNA, confirmed by hybridization techniques (Ostrow et al., 1990). Sobestiansky et al., (1999) described papillomatosis in pigs, affecting the skin, upper digestive tract and particularly the genital mucosa of females and males.

There are few studies on bird papillomavirus. Benign and malignant lesions in the mucosal epithelium of chaffinch (Fringilla coelebs) and bramling (Fringilla montifringilla) have been described in birds (Moreno-Lopez et al., 1984), as well as papilloma lesions of the African gray parrot (Psittacus erithacus timneh papillomavirus - PePV) (Terai et al., 2002).

Independent of species, PV types were based on their nucleotide sequence identity and according the Guidelines from the Papillomavirus Nomenclature Committee 1995 (Quebec, Canada), they were defined as a new papillomavirus type if the sequence of L1 ORF displayed less than $90 \%$ similarity with the L1 genes of all types known. So, putative new PV types had been amplified using primers FAP 59/FAP64 (Ogawa et al., 2004).

The objective of this study was to detect: (I) amplifications PVDNA using the FAP59/FAP64 primer in samples of healthy domestic and wild animals with no apparent clinical signs, (II) to analyze nucleotide sequence similarity of animal papillomavirus types to their closest related PV types and HPV sequences deposited in Gen Bank and (III) to diagnose papillomavirus-associated skin diseases in domestic and wild animals by histopathology.

\section{Material and Methods}

\section{Animals}

\section{Animals free of epithelial lesions}

Specimens (blood samples) were collected from the following domestic and wild animals: Ara ararauna, Ara chloroptera, Ara macao, Bos taurus, Bubalus bubalis, Canis familiaris, Equus caballus, Felis concolor, Ovis aries, Panthera onca, Sus domesticus and Struthio camelus. All animals in the study were free of warts lesions and clinically healthy.

\section{Wild animals and birds}

Two blood samples were collected from each one of wild animals at RioZoo Foundation (Felis concolor and Panthera onca). Both felines were adult and female.

One Ara chloroptera, one Ara macao, and eight Ara ararauna, all adults belonging to the Psittaciformes order, Psittacidae family, were mechanically contained for blood collection with an insulin needle containing EDTA.

Blood samples of ten ostriches of African Black breed (Struthio camelus) from Southern Rio de Janeiro at Saquarema municipality were also included in this study.

\section{Domestic mammals}

Blood samples of ten farm dairy cattle (Bos taurus) were selected in the Campos dos Goytacazes municipality at Northern Rio de 
Janeiro. Blood samples were collected from 12 buffalos (Bubalus bubalis) in the President Kennedy municipality, Espírito Santo State. The farm was dedicated to an extensive system of crossbred buffaloes.

Blood samples of ten ovines from São Francisco do Itabapoana and Campos dos Goytacazes municipality, Rio de Janeiro State, were collected. All animals were adult and female.

Six young swine Landrace $X$ Large White breed (Sus domesticus) from Northern Fluminense, Rio de Janeiro State, were selected also for blood collection from the ear vein or femoral vein using the anticoagulant ethylene diamine tetra aceticacid (EDTA).

Blood samples of twelve equines (Equus caballus) of the Rio de Janeiro Jockey Club aged between two and four years old, all thoroughbred, were also selected.

\section{Domestic animals with epithelial lesions}

\section{Canis familiaris}

Three dogs from Southwest of Rio de Janeiro (Canis familiaris) were also part of the study. Two dogs were Poodle and one was a Duchound breed showing warts-like lesions.

\section{Bos taurus}

Ten bovines were selected, six were females and four were males showing papillomas of several morphologies and on different anatomical regions.

\section{Wild animals with epithelial lesions}

\section{Sus scrofa}

Wart-like tumors of the tarsal region (lower limb) of Sus scrofa was extracted using sterile scalpel and tweezers after mechanical containment of the wild pigs in captivity proceeding from the southern region of Pantanal, Mato Grosso do Sul. Blood was also collected in vacutainer tubes containing anticoagulant EDTA.

\section{Ara ararauna}

Samples of adult macaws, Ara ararauna, were obtained from the RIOZOO Foundation Quarantine Center. Surgical removal of the lesion was performed using sterile scalpel and tweezers after chemical restraint with inhalation anesthesia in one of the macaws with lesions on the cloacal mucosa.

\section{Panthera leo}

One adult Panthera leo from the RIOZOO Foundation was sedated with anesthetic darts for therapeutic interventions. After verification of the presence of a papillomalike cauliflower lesion on the oral mucosa, the lion was sedated with ketamine and xylazine to collect the sample.

\section{Macaca fascicularis}

During routine visit to the Department of Primatology of the Laboratory Animal Breeding Center of the Oswaldo Cruz Foundation, Rio de Janeiro, one of the captive animals of the species Macaca fascicularis, 15 years-old, presented a typical flan papilloma-like clinically oral lesion. The sample was cataloged, extracted after sedation and preserved in formalin buffer for histopathology analysis.

\section{Histopathology}

About 18 biopsies from papillomas-like samples were collected and immersed in $10 \%$ formalin buffer solution embedded in paraffin (automated tissue processor TP1020, LEICA), micro-cuts of $5 \mu \mathrm{m}$ thickness (semiautomatic 
microtome RM2145, LEICA) and stained with haematoxylin and eosin ( $\mathrm{H}$ and $\mathrm{E})$.

\section{Molecular screening}

DNA extraction was carried out from blood samples and epithelial tissues from animals using QIAamp DNA blood and tissue mini kit following the manufacturer's protocol (Qiagen). The procedures for sample collection followed the standards of local research units according to each analyzed species. Blood collection was carried out using EDTA vacutainers tubes for each species.

\section{PCR amplifications}

Specimens DNA was amplified by polymerase chain reaction (PCR) with $\beta$ globin primers (sense: $5^{\prime}$ - AACCTCTT TGTTCACAACCAG - 3') / (antisense: 5' CAGATGCTTAACCCA CTGAGC - 3`) (Yaguiu et al., 2006). Degenerate primers pairs PCR FAP59 (forward: 5'TAACWGTIGGICAYCCWTATT - 3') and FAP64 (reverse: 5'- CCWATATCWV HCATITCICCATC - 3') were performed according Ogawa et al., (2004).

PCR was carried out in a volume of $50 \mu \mathrm{L}$ containing $2.5 \mu \mathrm{lDNA}$ sample, $0.5 \mu \mathrm{M}$ of each primer, $200 \mu \mathrm{M}$ dNTP mixture, $1.5 \mathrm{mM}$ $\mathrm{MgCl}_{2}$ and one unit of DNA Taq polymerase in $(20 \mathrm{mmol} / \mathrm{L}) 1 \mathrm{x}$ buffer Tris- $\mathrm{HCl} \mathrm{pH} 8.4$. PCR reactions were performed using negative control samples (high purified water) and positive control (HeLa cell DNA). Amplifications were performed with the following cycling profile: initial denaturation at $94^{\circ} \mathrm{C}$ for $10 \mathrm{~min}$ followed by 45 cycles of 1.5-min denaturation at $94^{\circ} \mathrm{C}, \quad 1.5$ minannealing at $50^{\circ} \mathrm{C}$, and 1.5 -min elongation at $72^{\circ} \mathrm{C}$. The last cycle was followed by a final extension of $5 \mathrm{~min}$ at $72^{\circ} \mathrm{C}$ (Ogawa et $a l ., 2004)$. All reactions were done in a PTC-
100 thermocycler. PCR DNA-specific bands were analyzed on a $2 \%$ agarose gel stained with ethidium bromide, visualized by UV light and photographed using Bio Doc Analyze (Biometra Ti5).

\section{Purification and sequencing}

PCR products were purified by GFX PCR DNA purification kit (GE Healthcare). Subsequently, $2 \mu \mathrm{l}$ of the purified PCR product was quantified and $5 \mu 1$ were used

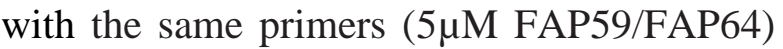
as in the amplification reaction for sequencing. This was performed using the BigDye ${ }^{\circledR}$ protocol (Applied Biosystems, USA) as described by the manufacturer. The chromatograms were first viewed using the Sequence Analyser software Base Caller Cimarron 3.12.

\section{Alignment}

The quality of the sequences obtained was evaluated by Chromas program version 2.33 and/or the Biological Sequence Aligment Editor (BioEdit), and the sequences obtained were compared with available sequences ofthe GenBank database using the Basic Local Alignment Search Tool program (BLAST) server (http://www.ncbi.nlm.nih. gov/blast/).

\section{Results and Discussion}

\section{Histopathology}

Histological examination of haematoxylin and eosin stained sections demonstrated epithelial hyperplasia, acanthosis, hyperkeratosis and tissue proliferation. Among the 18 samples microscopically examined, about 12 were diagnosed as papillomatosis (66.66\%), comprising bovines and primate; three samples from canine lesions were diagnosed as adenocarcinomas (16.66\%); one from 
macaw was diagnosed as nodular formations $(5.55 \%)$; one from the harvest of the wild pig, was diagnosed as melanoma $(5.55 \%)$; and finally, one was as fibrous epulic of the oral mucosa from lion $(5.55 \%)$.

Microscopic examination of cutaneous papillomatosis lesions showed alterations by pronounced hyperplasia of the stratum spinosum (acanthosis), associated with hyperkeratosis, sometimes parakeratotic and orthokeratotic and hypergranulosis, due to the exacerbation of the granular layer (with abundance of kerato-hyaline granules). Coilocytes and viral inclusion corpuscles were present also. The stromal, sparse and variably infiltrated by lymphocytelymphocytic cells with predominance of lymphocytes emitted papilliform projections.

The papillomatosis lesions in the primate revealed acanthosis, low hyperkeratosis, rare coilocytes and papillary support irregularly infiltrated by lymphocytes and plasmocytes. The absence of granulose was awesome. Samples from dogs revealed hyperkeratosis, inflammatory infiltrate of mononuclear cells, proliferation of sebaceous adenomas, sometimes exhibiting degrees of degeneration and cystic formations with presence of corneous pearls. These findings were identified as adenocarcinoma.

\section{Molecular analysis}

Based on the partial sequence of the L1 gene, of a total of the 75 blood samples analyzed by PCR from several species of animals, 31 biological specimens were positive to viral DNA amplifications of the eight species below: Ara chloroptera, Ara macao, Bos taurus, Canis familiaris, Felis concolor, Ovis aries, Panthera onca, Struthio camelus. Skin warts samples from bovines and canines were clinically and histopathologically previously diagnosed as papillomatosis (Figs 1 and 2).
The other species were free of papillomatosis lesions and clinically healthy. Only one of the 12 Bubalus bubalis samples showed viable genomic DNA after extraction. So, this species was excluded of the study.

Some positive samples had not enough genetic material for sequencing. Some samples showed noise after the sequencing which generated interference in the data analysis. Although the $\beta$-globin gene had been investigated in the domestic swine species, and all tested samples were considered eligible for PCR analysis of PV DNA sequences, bands amplified by PCR reaction using degenerate primers FAP59/FAP64 were not detected in blood samples. PV DNA bands were detected in skin biopsies and blood samples from bovines and canines with papillomatosis. It was possible to demonstrate that the genome of different animal species is strictly related with the genotypes of HPV by the analysis of the nucleotides sequence of the ORF L1.

Additionally, the fact that these strains are from diverse species and originally proceeding from distinct geographic regions indicates the phylogenetic proximity among hosts closely related at different nucleotide positions to papillomavirus types and HPV sequences deposited in Gen Bank. The alignment showed the overlapping of similar stretches of two sequences by Blast. The samples analyzed presented alignments with few nucleotides, varying according to the species investigated. Data about all samples in this study are summarized in tables 1 and 2 .

Bos taurus: BP28 samples showed alignment with 14 nucleotides of sequences of the Human papillomavirus type 97 (HPV-97) isolate W15189 (GenBank accession numbers EF2002168.1 - nt:215-228 and 6529-6516). About $100 \%$ identity was detected also with the HPV-97 isolate 624 complete genome 
(Access: EF436229.1 - nt:215-228 e 65296516), and with the HPV-97 complete genome (Access: DQ080080.1 - nt:215-228 e 6529-6516). 94\% similarity was also verified with Lynx rufus papillomavirus type 1 (LrPV1) complete genome (Access: AY904722.1) and $90 \%$ genetic similarity with the Human papillomavirus type 7 (HPV-7) E1 protein (E1) gene (Access: AF322243.1 - nt:151-170 e 32-12). BP29 samples showed100\% identity with Erethizon dorsatum papillomavirus type 1 EdPV-1 (Access: AY684126.1) and Ovine papillomavirus 1 (OvPV-1) complete genome (U83594.1).

Canis familiaris: In the clinically healthy canine (CP75), 17 nucleotides were aligned from sequences of isolates HPV L1 gene and L1 and L2 ORF of the HPV-5 (15nt), HPV-8 (15nt), -12 (15nt), -14 (21nt), -36 (15nt), -40 (17nt), -47 (15nt) and -82 (15nt).Alignment of the $90 \%$ identity was detected with Equus caballus papillomavirus type 1, (EqPV-1), complete genome (Access: AF498323.1) (18nt) and Equinus papillomavirus (EqPV-1), complete genome (Access: AF394740.1) (18nt). Another sample (CP98) detected 100\% identity in nucleotide positions (nt:639655 and 394-410) of the Human papillomavirus vs75-3 DNA, part of L1 ORF (Access: X79945.1), as well as $100 \%$ alignment of the nucleotide positions (nt: 642656 and 133-147) of the Human papillomavirus DNA for capsid protein L1 gene (clone vs203-2) (Access: X89880.1).

In the CP95 samples, 100\% identity of papillomaviruses of the European elk papillomavirus (EEPV) (15nt) and Reindeer papillomavirus (RPV) (15nt) were detected also. This sample showed 100\% homology with Human papillomavirus type 5, complete genome (Access: M17463.1); Human papillomavirus type $5 \mathrm{~L} 2$ and L1 genes (Access: $\quad$ DQ080001.1); Human papillomavirus type 5 DNA and naturally occurring deletions in the late region of the virus (Access: M22961.1); Human papillomavirus type 5b complete genome (Access: D90312.1); Human papillomavirus L2 protein (L2) gene, partial (Access: M73052.1); Human papillomavirus L2 protein (L2) gene sequence (Access: M730581 and M73056.1); Human papillomavirus type 8, complete genome (Access: M12737.1); Human papillomavirus type 12 genomic DNA (Access: X74466.1); Human papillomavirus type 36, complete genome (Access: U31785.1); and Human papillomavirus type 47 (Access: M32305.1).

The CP96 sample showed 94\% identity with Human papillomavirus type 40 genomic DNA (Access: X74478.1). The analyzed sample presented also a close relationship with the Human papillomavirus type 82 DNA, complete genome (Access: AB027021.1), showing $100 \%$ of alignment (nt:161-175 and 971-985).

The CP97 sample showed 94\% identity with the Human papillomavirus type 28 , complete genome (Access: U31783.1) and 85\% with the Human papillomavirus type 74 subtype AE10, complete genome (Access: AF436130.1). The similarity with another animal species were $90 \%$ with Trichosurus vulpecula papillomavirus major capsid protein L1 gene (Access: AF181682.1) and $76 \%$ identity with Bandicoot papillomatosis carcinomatosis virus type 2, complete genome (Access: EU277647.1).

Adenocarcinomatous cutaneous lesions (CP98 sample), of canines showed similarity with the L1 gene HPV (18nt) and with HPVs-6 (26nt), -7 (21nt), Human papillomavirus type 8 (HPV-8) (18nt), complete genome (Access: M12737.1), -28 (18nt), E6ORF Human papillomavirus type 31 (HPV-31) (19nt), 88\% identity with Human papillomavirus type 40 (HPV-40) (22nt) genomic DNA (Access: 
X74478.1) and (15nt) Human papillomavirus type74 (HPV-74) subtype AE10 (Access: AF436130.1). It also showed similarity with marsupial species, such as Bandicoot papillomatosis carcinomatosis virus 2 (33nt); Trichosurus vulpecula papillomavirus (19nt); 90\% identify with the dolphin Tursiops truncatus papillomavirus type 2 (18nt) and 88\% with primate Pygmy Chimpanzee papillomavirus type 1 (22nt) (Access: X62844.1).

In the wild feline research, Panthera onca designed PoP46 sample, was aligned with 16 nucleotides of Human papillomavirus type 7 HPV-7 (Access: X74476.1- nt: 848-863 and nt: 2319-2274), a viral type of a tropical common skin wart. Felis concolor showed a closer relationship (18nt) with Human papillomavirus type 84 - HPV-84, complete genome (Access: AF293960.1) and 94\% similarity (17nt) with Human papillomavirus type 87 - HPV-87 (candidate) complete genome (Access: AJ400628.2), respectively. Struthiocamelus: Struthio camelus samples identified as SP42 and 43were selected for sequencing. Nearly18 nucleotides (nt: 64-81 and 3623-3640) were aligned with Human papillomavirus type 74 (HPV-74) subtype AE10, complete genome (Access: AF436130.1) and 94\% similarity with Human papillomavirus type 107 (HPV-107) complete genome (Access: EF422221.1), respectively. Genetic identity showed $81 \%$ similarity (30nt) with Human papillomavirus type 34 (HPV34) genomic DNA (Access: X74476.1) and $88 \%$ similarity (22nt) with Bovine papillomavirus type 3 (BPV-3), complete genome (Access: AF486184.1; AJ620207.1). Ara macao: of the Ara macao species designated AP45 sample, 16 nucleotides were aligned with Uncia uncia papillomavirus type 1 (UuPV-1) (Access: DQ180494.1).

Some histopathological samples were diagnosed as other dermatopathies similar to the cases of inflammatory dermatitis described by Yuan et al., (2007). The findings of papillary lesion were similar to those detected in Erethizon dorsatum PV (EdPV-1), with hyperplastic epidermal regions (acanthosis and orthokeratous hyperkeratosis), with coylocytes in the granular stratum and in the corneum stratum (Rector et al., 2005). Similarly, we found the histological findings of $\mathrm{PV}$ infection in samples of Asian lions (Panthera leopersica) (Sundberg et al., 1996).

Identical microscopic alterations were also found by Maeda et al., (2007) in the epidermal proliferation with hyperplasia and acanthosis in the corneum stratum and cutaneous warts from the teats of cows affected by papillomatosis by histological analysis. As well as the histopathological analysis of the oral lesions of the polar bear (Ursus maritimus) revealed epithelial hyperplasia with formation of dermal papillae and orthokeratotic hyperkeratosis (Stevens et al., 2008), similar histological alterations were also found in this study.

Macroscopically, circular and sessile projections, with flat surfaces and pink coloration, as described by Maeda et al., (2007), were also observed in this present study analyzing biopsies fragments of the oral mucosa of the Asian lion (Panthera leo persica) and Cynomolgus primate (Macaca fascicularis).Both lesions showed the same micro- and macroscopic histological changes, independently of epithelial differentiation of the papilloma virus host.

\section{Molecular}

The PCR reaction used in this study matches with the molecular data by applying generic primers that amplify the L1 gene, the most conserved and stable region of the viral genome among all types of papillomaviruses. 
The pair of generic primers targeted to the gene of interest was the degenerate FAP59 / FAP64, designed by Forslund et al., (1999), from human tumor samples, applied also by Ogawa et al., (2004), to detect cutaneous tumors of HPV types and normal skin samples.

Following the methodology proposed by Antonsson and Hansson (2002) and Ogawa et al., (2004), the main strategy for identification of the present PV types has been the partial amplification of papillomavirus L1 gene of human and animal origin. These strategies have employed degenerate primers for the amplification by PCR to be able to identify not only the HPV types previously described, but also to detect possible new virus subtype viruses in humans and animal species (Claus et al., 2007). Other researchers as Antonsson and McMillan (2006) and Maeda et al., (2007) detected the presence of PV DNA using the same pair of generic primers FAP59/FAP64, using swab samples from healthy epithelium of Australian animals and warts of cow teats respectively.

Table.1 Nucleotide sequences identity of animal papillomavirus types from papilloma specimens (wart and/or blood samples) compared to their closest related HPV sequences deposited in Gen Bank

\begin{tabular}{|c|c|c|c|c|}
\hline Samples* & Species & Identity & Gen Bank & Acession \\
\hline BP28 & Bos taurus & $100 \%$ & $\begin{array}{l}\text { Human papilomavírus type } 97 \text { isolate } \\
\text { W15189,complete genome }\end{array}$ & EF2002168.1 \\
\hline $\mathrm{CP} 75$ & Canis familiaris & $91 \%$ & $\begin{array}{l}\text { Human papilomavírus isolate HPVX14 L1 protein } \\
\text { gene }\end{array}$ & AF498323.1 \\
\hline CP78 & Canis familiaris & $100 \%$ & Human papillomavirus DNA L1 gene (clone vs203-2) & X89880.1 \\
\hline CP95 & Canis familiaris & $100 \%$ & Human papillomavirus type $5 \mathrm{~L} 2$ & DQ080001.1 \\
\hline CP95 & Canis familiaris & $100 \%$ & Human papillomavirus type 47 & M32305.1 \\
\hline CP95 & Canis familiaris & $100 \%$ & Human papillomavirus type 8 , complete genome & M12737.1 \\
\hline CP95 & Canis familiaris & $100 \%$ & Human papillomavirus type 36 , complete genome & U31785.1 \\
\hline CP96 & Canis familiaris & $100 \%$ & $\begin{array}{l}\text { Human papillomavirus type } 82 \text { DNA, complete } \\
\text { genome }\end{array}$ & AB027021.1 \\
\hline CP96 & Canis familiaris & $94 \%$ & Human papillomavirus type 40 genomic DNA & X74478.1 \\
\hline CP97 & Canis familiaris & $94 \%$ & Human papillomavirus type 28 , complete genome & U31783.1 \\
\hline CP98 & Canis familiaris & $100 \%$ & $\begin{array}{l}\text { Human papillomavirus type } 74 \text { AE10, complete } \\
\text { genome }\end{array}$ & AF436130.1 \\
\hline ScP42 & Struthio camelus & $100 \%$ & Human papillomavirus type 74 subtype AE10 & AF436130.1 \\
\hline $\mathrm{ScP} 43$ & Struthio camelus & $94 \%$ & Human papillomavirus type 107, complete genome & EF422221.1 \\
\hline PoP46 & Panthera onca & $100 \%$ & Human papillomavirus type 7 & $\mathrm{X} 74463.1$ \\
\hline FcP47 & Felis concolor & $94 \%$ & Human papillomavirus type 87 , complete genome & AJ400628.2 \\
\hline FcP47 & Felis concolor & $90 \%$ & Human papillomavirus type 84 , complete genome & AF293960.1 \\
\hline
\end{tabular}

*Samples: BP: Bovinepapillomavirus; CP: Caninepapillomavirus; ScP: Struthio papillomavirus; PoP: Panthera onca papillomavirus; FcP: Felis concolor papillomavirus 
Table.2 Nucleotide sequences identity of animal papillomavirus types from papilloma specimens (wart and/or blood samples) compared to their closest related others PV sequences deposited in Gen Bank

\begin{tabular}{|l|c|c|l|l|}
\hline Samples* & Species & Identity & \multicolumn{1}{|c|}{ Gen Bank } & Acession \\
\hline BP 28 & Bos taurus & $94 \%$ & Lynx rufus papilomavirus type 1, complete genome & AY904722.1 \\
\hline BP29 & Bos taurus & $100 \%$ & $\begin{array}{l}\text { Erethizondorsatum papillomavirus type 1, complete } \\
\text { genome }\end{array}$ & AY684126.1 \\
\hline BP29 & Bos taurus & $100 \%$ & Ovine papillomavirus 1, complete genome & U8359.1 \\
\hline CP75 & Canis familiaris & $90 \%$ & Equus caballus papillomavirus type 1 & AF498323.1 \\
\hline CP75 & Canis familiaris & $90 \%$ & Equinus papillomavirus, complete genome & AF394740.1 \\
\hline CP95 & Canis familiaris & $100 \%$ & European elk papillomavirus & AF45953.1 \\
\hline CP95 & Canis familiaris & $100 \%$ & Reindeer papillomavirus & AF181682.1 \\
\hline CP97 & Canis familiaris & $90 \%$ & Trichosurus vulpecula papillomavirus & EU277647.1 \\
\hline CP97 & Canis familiaris & $76 \%$ & Bandicoot papillomatosis carcinomatosis virus type 2 & AY956402.1 \\
\hline CP98 & Canis familiaris & $90 \%$ & $\begin{array}{l}\text { Tursiops truncates papillomavirus type 2, complete } \\
\text { genome }\end{array}$ & X62844.1 \\
\hline CP98 & Canis familiaris & $88 \%$ & Pygmy chimpanzee papillomavirus type 1 DNA & AF486184.1 \\
\hline SP43 & Struthio camelus & $88 \%$ & Bovine papillomavirus type 3, complete genome & DQ180494.1 \\
\hline AP45 & Ara macao & $100 \%$ & Uncia uncia papillomavirustype 1 &
\end{tabular}

*Samples: BP: Bovine papillomavirus; CP: Canine papillomavirus; SP: Struthio papillomavirus; AP: Ara macao papillomavirus

Fig.1 Histological changes of cutaneous papillomatosis in bovine, $\mathrm{H}$ and $\mathrm{E}$. The arrows indicate: A) Kerato-hyaline granules at the dermo-epidermal junction; B) Formation of interpapillary ridges, presence of acanthosis and hyperkeratosis; C) Proliferation of connective tissue characteristic of fibropapilloma; D) Basophilic Intranuclear Inclusion Corpuscle. Magnifications: A - 200x, B - 50x, C - 100x, D - 400x

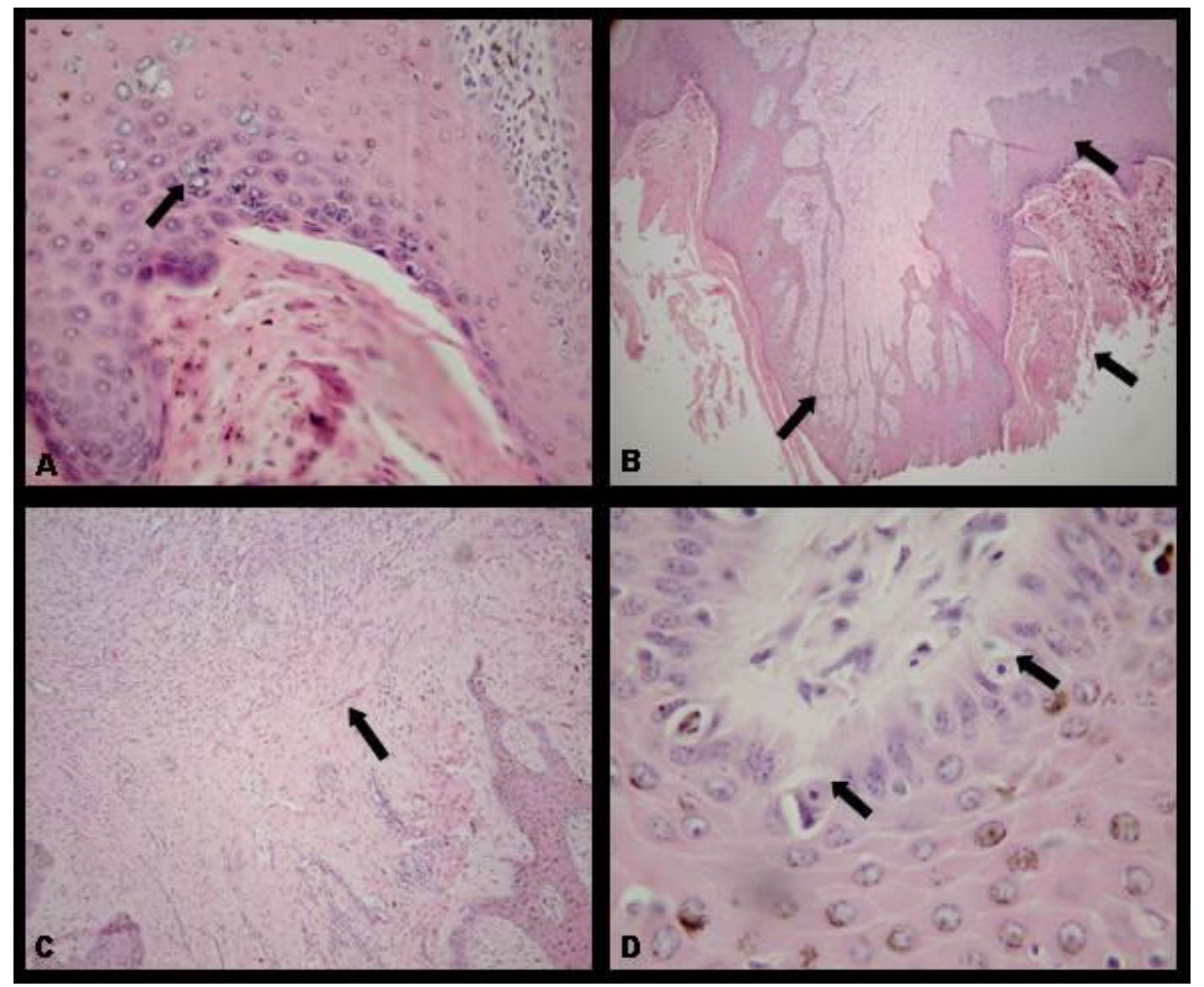


Fig.2 Histological changes of bovine cutaneous papillomatosis (A and B) and papillomatosis of oral mucosa of primate ( $\mathrm{C}$ and $\mathrm{D})$ by $\mathrm{H}$ and $\mathrm{E}$. The arrows indicate: A) Tissue infiltrated by lymphoplasmacytic cells with predominance of lymphocytes; B) Hyperkeratosis and hypergranulosis due to exacerbation of the granular layer by the formation of granulations; C) Vacuolated basal cell in cell division compatible with the initiation of viral replication; D) Low hyperkeratosis evidencing the connective axis by lymphocytes and plasma cells. Magnifications: A - 200x, B - 200x, C - 400x, D - 100x

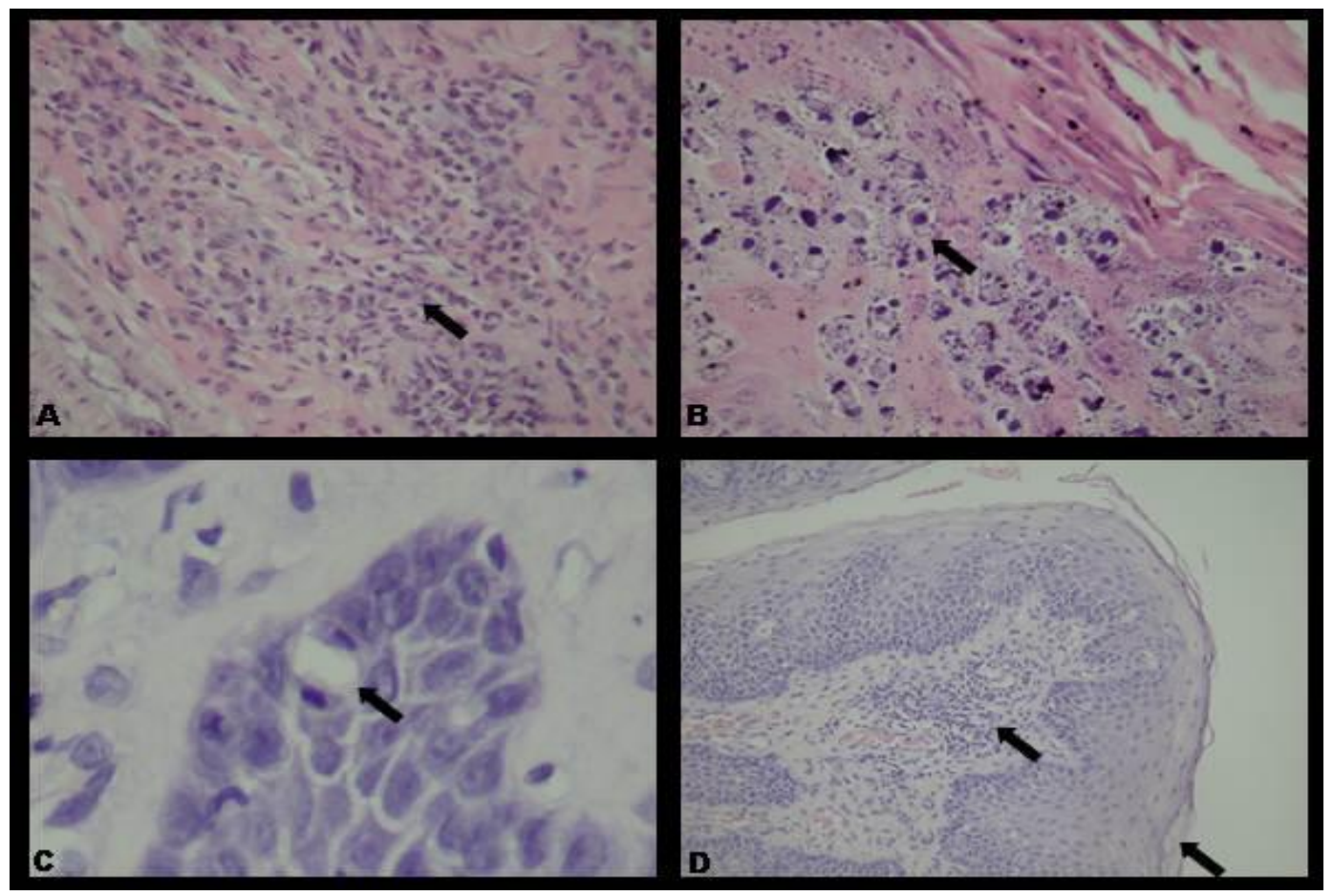

The findings in canine samples in the present study are in accordance with data described by Tanabe et al., (2000), when identifying viral DNA sequences in cutaneous samples of canines, and are in agreement also with Claus et al., (2007) for amplified fragments from bovine papillomas. Viral DNA sequences have been detected in samples of bovine papillomas (Ogawa et al., 2004; Claus et al., 2007), oral lesions of wild animals (Sundberg et al., 1996; Stevens et al., 2008), intact epithelial swabs from Australian animals (Antonsson and McMillan, 2006) and genital mucosa swabs from non-human primates (Mello, 2005).

This study detected DNA PV in the blood samples of animal species of the Brazilian fauna with and without clinical manifestation of the papillomavirus infection, which had not yet been investigated. Therefore nonamplification detected from whole blood samples of the same species investigated probably was due to the presence of the virus limits below detection, or the PV present was not detectable by the use of primers for analysis in the region L1, with possible deletions of the gene of the test sample and loss of chromosomal material.

However, the findings of the present study corroborate with Mello (2005) that the PV presence in asymptomatic animals is not always easy to detect. The detection of PV nucleotide sequences in animal species were generally not amplified, emphasizing their non-specificity. 
Despite the recent studies of avian papillomatosis, PV infection have been described from samples of squamous papillomas in species of closely related finches, chaffinch (Fringilla coelebs papillomavirus - FPV), bramling (Fringilla montifringilla papillomavirus) and African gray parrot (Psittacus erithacus timneh papillomavirus - PePV) (Moreno-Lopez et al., 1984; Terai et al., 2002). In the present study, PV DNA sequences were amplified from blood samples from clinically healthy birds of species not yet investigated, such as Ara chloroptera, Ara macao and Struthio camelus. So, this is the first record of PV infection in these species.

The similarities of the nucleotide sequences were determined by Ogawa et al., (2004) with putative new PV types using the same pair of primer FAP59/FAP64 applied in this present study. Previous reports showed latent or subclinical infection of PV from healthy skin of humans and animals (Antonsson and Hansson, 2002) as well as the samples tested with latent and subclinical infection of the several species investigated. According to American research, new PV infection was detected in the species Trichechusma natuslatirostris, amplifying fragment with 478 bp using the MY09 / MY11 oligonucleotide pair (Woodruff et al., 2005).In a Koala sample, identified as KoPV, a band of $440 \mathrm{bp}$ was detected, using the same primers used in the present study (Antonsson and McMillan, 2006).

But the sensitivity of the FAP59/FAP64 PCR was higher than that of the MY09/MY11 PCR for DNA PV samples. Therefore, the samples of this paper were tested only for degenerate primer FAP. Essentially, these alignments should indicate a homology between the sequences. In other words, homology indicates having evolutionary significance with similarity between sequences sharing the same ancestry.
So, this study demonstrated the nucleotide sequence similarity of animal papillomavirus types to their closest related PV types and HPV sequences deposited in Gen Bank indicating a phylogenetic proximity among the investigated hosts.

In addition, healthy domestic and wild animals with no apparent clinical papilloma signs suggest latent or subclinical infections of PV types. Our results showed PV DNA amplifications detected by using FAP59/FAP64. This same primer had been used also by Antonsson and Hansson (2002) and Ogawa et al., (2004) as PCR based on highly conserved regions within the L1 open reading frame (ORF).

Size variations of the amplified fragments within a same species and among different animal species were shown in the present study. These variations were also found by Forslund et al., (1999), when detecting 12 probable new types of HPVs with variations of $434 \mathrm{bp}, 437 \mathrm{bp}, 440 \mathrm{bp}$ and $446 \mathrm{bp}$ sizes of the generated fragments. The majority of HPVs amplified a 478 bp fragment using the degenerate primer pair FAP59/FAP64. But other types as HPV-40 amplified a 740 bp fragment and HPV-58 amplified 264bp.

Thus, this study showed a high diversity of the Papillomaviridae family in diagnosed papillomaviruses infections. The amount of nucleotides aligned by identity demonstrated all other possible alignments considering the probability that the alignment has been occurred randomly by genetic similarity comparing closest related PV types and HPV sequences deposited in Gen Bank.

\section{References}

Antonsson A., McMillan, N.A.J. 2006. Papillomavirus in healthy skin of Australian animals. J. General Virol., 87: 3195-3200. 
Antonsson, A., Hansson, B.G. 2002. Healthy skin of many species harbors papilomaviruses which are closely related to their human counterparts. J. Virol., 76(24):12537-12542.

Chan, S.Y., Bernard, H.U., Ratterree, M., Birkebak, T.A., Faras, A.J., Ostrow, R. 1997.Genomic diversity and evolution of papillomaviruses in Rhesus Monkeys. $J$. Virol., 71(7): 4938-4943.

Claus, M.P., Vivian, D., Lunardi, M., Alfieri, A.F., Alfieri, A.A. 2007. Phylogenetic analysis of bovine papillomavirus associated with skin warts in cattle herds from the state of Paraná. Pesquisa Veterinária Brasileira, 27(7): 314-318.

Forslund, O., Antonsson, A., Nordin, P., Hansson, B.G. 1999.A broad range of human papillomavirus types detected with a general PCR method suitable for analysis of cutaneous tumors and normal skin. J. General Virol., 80: 2437-2443.

Ghim, S.J., Newsome, J., Bell, J., Sundberg, J.P., Schlegel, R., Jenson, A.B. 2000. Spontaneous regressing oral papillomas induce systemic antibodies that neutralize canine oral papillomavirus. Experimental and Mol. Pathol., 68: 147- 151.

Hanna, P.E., Dunn, D. 2003. Cutaneous fibropapilloma in a cat (feline sarcoid). Canadian Vet. J., 44: 601-602.

Huber, B., Schellenbacher, C., Shafti-Keramat, S., Jindra1, C., Christensen, N., Kirnbauer, R. 2017. Chimeric L2-Based Virus-Like Particle (VLP) Vaccines Targeting Cutaneous Human Papillomaviruses (HPV). PLOS ONE, 127.

Karstad, L., Kaminjolo, J.S. 1978. Skin papillomas in an impala (Aepyceros melampus) and a giraffe (Giraffaca melopardalis). J. Wildlife Dis., 14: 309313.

Maeda, Y., Shibahara, T., Wada, Y., Kadota, K., Kanno, T., Uchida, I., Hatama, S. 2007. An outbreak of teat papillomatosis in cattle caused by bovine papilloma virus (BPV) type 6 and unclassified BPVs. Vet. Microbiol., 121: 242-248.
Marins, R.S.Q.S, Cassiano, K.M., Pereira, S.R.F.G., Nogueira, D.M., Carvalho, E.Q.2012. Canine latent papillomavirus infection and chromosomal in stability studies in peripheral blood lymphocytes and tumors cells cultures from lesions biopsy. Int. Res. J. Biochem. Bioinformatics, 2(3): 62-68.

Marins, R.S.Q.S, Nogueira, D.M., Pereira, S.R.F.G., Cassiano, K.M., Maues, T., Dias, V.G., Moreira, L., Carvalho, E.C.Q. 2010. Cytogenetic studies: Premature chromosome condensation (PCC) in peripheral blood lymphocytes cultures and skin lesions cultures induced by Papillomavirus spontaneous infection in bovines. Revista de CiênciasMédicas $e$ Biológicas, 9(1): 3-9.

Mello, W.A. 2005. Investigação de papilomavírus em primatas não-humanos do Novo Mundo: ocorrência e caracterização molecular. Tese de Doutorado, Biologia de Agentes Infecciosos e Parasitários, Universidade Federal do Pará - UFP, Belém, p. 115.

Moreno-Lopez, J., Ahola, H., Stenlund, A., Osterhaus, A., Pettersson, U. 1984.Genome of an Avian Papillomavirus. J. Virol., 51(3): 872-875.

Nicholls, P.K., Klaunberg, B.A., Moore, R.A., Santos, E.B., Parrys, N.R., Gough, G.W., Stanley, M.A. 1999. Naturally occurring, non regressing Canine Oral Papilloma virus infection: host immunity, virus characterization, and experimental infection. Virol., 265: 365-374.

Ogawa, T., Tomita, Y., Okada, M., Shinozaki, K., Kubonoya, H., Kaiho, I., Shirasawa, H. 2004. Broad-spectrum detection of papilloma viruses in bovine teat papillomas and healthy teat skin. $J$. General Virol., 85: 2191-2197.

Ostrow, R.S., McGlennen, R.C., Shaver, M.K., Kloster, B.E., Houser, D., Faras, A.J. 1990. A Rhesus monkey model for sexual transmission of a papilloma virus isolated from a squamous cell carcinoma. Proceedings of National Academy Sci., 
87: 8170-8174.

Rector, A., Tachezy, R., Doorslaer, K.V., MacNamara, T., Burk, R.D., Sundberg, J.P., Ranst, M.V. 2005.Isolation and cloning of a papillomavirus from a North American porcupine by using multiply primed rolling-circle amplification: the Erethizondorsatum papillomavirus type 1. Virol., 331: 449-456.

Simões, R.S.Q., Barth, O.M. 2015. Papillomavirus: Viral vectors in the gene therapy and new therapeutic targets. Int J. Biomed. Res., 6(10): 763-768.

Simões, R.S.Q., Barth, O.M. 2016. Chromosome aberrations as a biomarker for genomic instability in cell cultures originated from bovines, canines and equines infected with papillomavirus. Int. J. Appl. Sci. Biotechnol., 4(1): 104112.

Simões, R.S.Q., Barth, O.M. 2017. Immunological and structural analysis of HPV-positive cervical carcinoma cell lines and bovine papilloma virus viruslike particles (BPV-VLP). Int. J. Adv. Res., 5(4): 1003-1009.

Sobestiansky, J., Barcellos, D.E.S.N., Mores, N., Oliveira, S.J., Carvalho, L.F.O.S., Moreno, A.M., Roehe, P.M. 1999. Papilomatose. In: Clínica e Patologia Suína. 2.ed. Goiânia: Art 3 Impressos Especiais, $464 \mathrm{p}$.

Stevens, H., Rector. A., Bertelsen, M.F., Leifsson, P.S, Van Ranst, M. 2008. Novel papillomavirus isolated from the oral mucosa of a polar bear does not cluster with other papilloma viruses of carnivores. Vet. Microbial., 129: 108-116.

Sundberg, J.P., Montali, R.J., Bush, M., Phillips, L.G., O`Brien, S.J., Jenson, A.B., Burk, R.D., Van Ranst, M. 1996.
Papillomavirus-associated focal oral hyperplasia in wild and captive asian lions (Panthera leo persica). J. Zoo and Wildlife Med., 27: 61-70.

Sundberg, J.P., Van Ranst, M., Montali, R., Homer, B.L., Miller, W.H., Rowland, P.H., Scott, D.W., England, J.J., Dunstan, R.W., Mikaelian, I., Jenson, A.B. 2000. Feline papillomas and papillomaviruses. Vet. Pathol., 37: 1-10.

Tanabe, C., Kano, R., Nagata, M., Nakamura, Y., Watanabe, S., Hasegawa, A. 2000. Molecular characteristics of cutaneous papillomavirus from the canine pigmented epidermal nevus. J. Vet. Med. Sci., 62(11): 1189-1192.

Terai, M., Desalle, R., Burk, R.D. 2002. Lack of canonical E6 and E7 Open reading Frames in bird Papillomaviruses: Fringilla coelebs Papillomavirus and Psittacus erithacus timneh Papillomavirus. J. Virol., 76(19): 1002010023.

Tomita, Y., Ogawa, Y., Jin, Z., Shirasawa, H. 2007. Genus specific features of bovine papillomavirus E6, E7, E5 and E8 proteins. Virus Res., 124: 231-236.

Yaguiu, A., Carvalho, C., Freitas, A.C., Góes, L.G.B., Dagli, M.L.Z., Birgel Jr, E.H., Beçak, W., Stocco Dos Santos, R.C. 2006. Papillomatosis in cattle: in situ detection of bovine papilomavírus DNA sequences in reproductive tissues. Brazilian J. Morphol. Sci., 23(3/4): 129136.

Yuang, Z., Philbey, A.W., Gault, E.A., Campo, M.S., Nasir, L. 2007. Detection of bovine papillomavirus type 1 genomes and viral gene expression in equine inflammatory skin conditions. Virus Res., 124: 245-249.

\section{How to cite this article:}

Dra. Rachel Siqueira de Queiroz Simões and Dra. Ortrud Monika Barth. 2017. Papillomavirus (PV) - Associated Skin Diseases in Domestic and Wild Animals: Animal Nucleotide Sequence Identity of PV Types to their Closest Related PV and HPV Sequences Deposited in the Gen Bank. Int.J.Curr.Microbiol.App.Sci. 6(7): 938-951. doi: https://doi.org/10.20546/ijcmas.2017.607.115 